\title{
Urban Heat Island High Local Water-Vapor Feedback Estimates Requiring Albedo Management
}

\author{
Alec Feinberg ( $\nabla$ dfrsoft@gmail.com ) \\ Northeastern University https://orcid.org/0000-0003-4364-2460
}

\section{Research Article}

Keywords: Water-vapor feedback, Urban Heat Islands, lapse rate, humid climates, dry climates, WAVHIS, MODIS

Posted Date: February 23rd, 2021

DOl: https://doi.org/10.21203/rs.3.rs-187427/v1

License: (9) This work is licensed under a Creative Commons Attribution 4.0 International License. Read Full License 
A. Feinberg, DfRSoft Research

Abstract

In this paper, we analyze warming data on Urban Heat Islands (UHI) in dry versus humid environments to estimate local water-vapor feedback from city growth. We find looking at such data and comparing rural to urban areas, UHI local water-vapor feedback is about $3 \mathrm{~W} / \mathrm{m}^{2} /{ }^{\circ} \mathrm{K}$ to a maximum of $4 \mathrm{~W} / \mathrm{m}^{2} /{ }^{\circ} \mathrm{K}$. Relative to global climate feedback estimates of about $2 \mathrm{~W} / \mathrm{m}^{2} /{ }^{\circ} \mathrm{K}$, this is a factor of 1.5 to 2 times higher. This UHI effect is observed during daytime hours. Water-vapor feedback is known to be one of the most important in our climate system and thought that it can double the direct known forcing and is found here to be an even stronger UHI local effect. We suspect with city growth there is a loss of natural convection cooling and an increase in dome heat/humidity from UHI impermeable surfaces since warm air holds more water-vapor creating a local greenhouse gas (GHG). These are key contributors to local water-vapor feedback raising local temperatures in humid cities. An optimum way to mitigate this effect is with UHI albedo management. We suggest that this warming effect can be an important factor in UHI global warming contributions and should be mitigated.

Key Words: Water-vapor feedback, Urban Heat Islands, lapse rate, humid climates, dry climates, WAVHIS, MODIS

\section{Introduction:}

Observation of excess water-vapor steaming off hot city roads and surfaces during precipitation (black roofs, black roads, black cars, etc.) is commonplace due to city growth. This is a gross observation that is easy to detect during precipitation periods in UHIs. However, subtle effects due to warm air created from hot impermeable surface growth have increased local atmospheric water-vapor in UHIs even in heat domes at higher altitudes compared to rural areas since warm air holds more water-vapor. In general, atmospheric WAter-Vapor due to Hot Impermeable Surfaces (WAVHIS) is a key factor for increasing local humidity feedback and its temperatures where city growth has occurred and is strongly correlated to precipitation periods [1]. Water-vapor is the most important GHG in the atmosphere.

In this paper, we present two different analyses based on data taken from a Zhao et al. [1] study to illustrate UHI water-vapor feedback. Although not well studied as a local UHI feedback effect, we can point to several known humidity effects:

1. Zhao et al. [1] observed that UHI temperatures increase in daytime $\Delta \mathrm{T}$ by $3.3^{\circ} \mathrm{C}$ in humid compared to dry climates. They found a strong correlation between $\Delta \mathrm{T}$ increase and daytime precipitation stating, "the daytime $\Delta \mathrm{T}$ has a discernible spatial pattern that follows precipitation gradients across the continent. Twenty-four of the cities are located in the humid southeast United States, which coincides roughly with the Koppen-Geiger temperate climate zone. Their daytime annual-mean $\Delta \mathrm{T}$ is on average $3.9^{\circ} \mathrm{K}$ and is $3.3^{\circ} \mathrm{K}$ higher than that of the 15 cities in the dry region. By comparison, the night-time $\Delta \mathrm{T}$ differs by $0.1^{\circ} \mathrm{K}$ between the two groups." Their results concluded that albedo management would be a viable means of reducing $\Delta \mathrm{T}$ on large scales.

Zhao et al. [1] described the effect as "largely explained by variations in the efficiency with which urban and rural areas convect heat to the lower atmosphere. If urban areas are aerodynamically smoother than surrounding rural areas, urban heat dissipations are relatively less efficient, and urban warming occurs (and vice versa)." Other authors have also detailed UHI convection cooling losses (Gunawardena et al [2]). However, while this is a plausible explanation of reduced cooling [2], it does not strongly explain Zhoa et al.'s nighttime observations. As well, smooth impermeable surfaces create high evaporation rates which do provide some amount of rapid convection surface cooling. We suggest that WAVHIS GHG likely could play a reasonable role in this UHI daytime warming since dome and surface air over cities is warmer (Fan et al. [3]) compared to neighboring rural atmosphere. Since warm air holds more water-vapor, this could promote a local GHG effect in precipitation periods. In particular, since daytime surface and atmospheric temperatures are hotter, and this effect correlates to daytime precipitation events [1], this appears to be a plausible explanation for the difference between the days vs. night Zhao et al. observations. This type of warming to a lesser extend may occur on all smooth evaporating surfaces where temperatures are hottest (during 
precipitation periods) including roads and highways. No matter the actual mechanism, the observed data shows a certain amount of additional warming in humid compared to dry UHI environments.

2. In a study of wetland reduction in China and its correlation to drought, Cao et. al. [4] looked at the wetland distributions and areas for five provinces due to urbanization. These areas showed a total reduction in southwestern China from 1970 to 2008 of $17 \%$ ground area, with the highest reduction rate occurring from 2000 to 2008. They found these changes to the wetland area showed a negative correlation with temperature (i.e. wetland decrease, increase in temperature), and a positive correlation with precipitation (i.e. wetland decrease, precipitation decrease). We suggest that loss of wetland and increases in urbanization drove warmer temperature over land through a combined situation; a loss of condensing moisture, atmospheric water-vapor increase, along with the decrease in wetland natural evaporation cooling contributions has a compounding dryness effect impacting the rain budget.

3. Such UHI related issues can contribute to drought. Drought feedback leads to forest fire feedbacks that not only damages forests that would otherwise remove $\mathrm{CO}_{2}$ from the air, but that also releases $\mathrm{CO}_{2}$ and other GHGs into the atmosphere. Therefore, this is a major offset in $\mathrm{CO}_{2}$ worldwide reduction efforts. This suggests the urgent need for supplementary albedo reverse forcing efforts.

4. Novel data from the Atmospheric Infrared Sounder (AIRS) on NASA's Aqua satellite precisely measures the humidity throughout the lowest 10 miles of the atmosphere. The imagery is capture in a video [5] illustrating hot areas over the Earth where concentrated amounts of water-vapor over land and numerous areas like LA, and cities in South America, Africa, India, and so forth. Countries and cities in warm areas are experiencing atmospheric humidity in all altitudes of the troposphere. This is increasing over time according to Dessler et al. $[6,7]$ research and could also be partly due to atmospheric WAVHIS issues. Dessler attributed it mainly to ocean evaporation due to $\mathrm{CO}_{2}$ warming. His results were for average feedback for various altitudes finding $2.04 \mathrm{~W} / \mathrm{m}^{2} /{ }^{\circ} \mathrm{K}$. However, their study did not focus on any related aspects of UHI growth.

\section{Method and Data}

From the Stefan-Boltzmann equation the dry climate difference estimate can be written for dry climates as

$$
\left(\frac{P_{U}}{\varepsilon \sigma}\right)_{D r y}^{1 / 4}-\left(\frac{P_{R}}{\varepsilon \sigma}\right)_{D r y}^{1 / 4}=\left(T_{U}-T_{R}\right)_{D r y}=\Delta T_{D r y}
$$

We denoted $\mathrm{U}$ for urban and $\mathrm{R}$ for rural and letting

$$
\Delta P^{1 / 4}=\left(P_{U}^{1 / 4}-P_{R}^{1 / 4}\right)
$$

allows us to write

Similarly in wet climates

$$
\Delta P_{D r y}=\sigma \varepsilon \Delta T_{D r y}^{4}
$$

$$
\Delta P_{W e t}=\sigma \varepsilon\left(T_{U}-T_{R}\right)_{W e t}^{4}=\sigma \varepsilon \Delta T_{W e t}^{4}
$$

We then denote the second difference radiation flux estimate $\Delta P_{\Delta W-\Delta D}$ as

$$
\Delta P_{\Delta W-\Delta D}=\Delta P_{W e t}-\Delta P_{D r y}=\sigma \varepsilon\left(\Delta T_{W e t}^{4}-\beta \Delta T_{W e t}^{4}\right)
$$

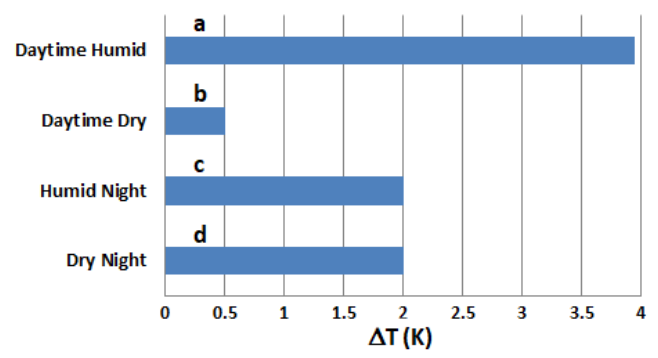

Figure 1 Key estimates taken from Zhao et al. [1] MODIS $\Delta$ T data (see their Fig. 2 [1]) values assessed are a) daytime value of humid cities, b) daytime in wet cities, c) and d) are night humid and dry cities 
An estimate from Zhao et al. data (see Fig. 1a, b), indicates on average $\Delta \mathrm{T}_{\mathrm{We}} \approx 3.95^{\circ} \mathrm{K}$ and $\Delta \mathrm{T}_{\mathrm{We}} \approx 0.5^{\circ} \mathrm{K}$ (taken from their NASA MODIS $\Delta \mathrm{T}$ data in their Fig. 2d, e) providing an estimate of

$$
\Delta P_{\Delta W-\Delta D}=\sigma \varepsilon\left(\Delta T_{W e t}^{4}-\beta \Delta T_{D r y}^{4}\right)=\sigma 0.63\left(3.95^{4}-0.5^{4}\right)=10.3 \mathrm{~W} / \mathrm{m}^{2}
$$

where we take $\varepsilon=0.63$ (see Feinberg [8]). We note this is not observed in (Fig 1c, d) Zhao et al. [1] data for nighttime humid vs dry effect. Then the second difference water-vapor feedback in Eq. 6 is

$$
\bar{\lambda}_{\Delta W-\Delta D}=\frac{\Delta P_{\Delta W-\Delta D}}{\left(\Delta T_{\text {Humid }-D r y}\right)_{D a y}}=\frac{10.3 \mathrm{~W} / \mathrm{m}^{2}}{3.3^{\circ} \mathrm{K}}=3.12 \mathrm{~W} / \mathrm{m}^{2} /{ }^{\circ} \mathrm{K}
$$

where $\left(\Delta T_{\text {Humid-Dry }}\right)_{\text {Day }}=3.3^{\circ} \mathrm{K}$ is from Zhao et al.'s data in humid compared to dry climates. The second difference feedback using $\Delta P_{\Delta W-\Delta D}$ is one metric and it would be good to simplify. Therefore, assume $\mathrm{T}_{\mathrm{R}-\mathrm{Dry}}=\mathrm{T}_{\mathrm{R}_{-} \text {Wet }}$ for the rural areas. This allows us to write a more straight-forward difference radiation flux given as

$$
\Delta P_{W_{U}-D_{U}}=\left(P_{W e t_{-} U}-P_{W e t_{-} R}\right)-\left(P_{D r y_{-} U}-P_{D r y_{-} R}\right)=P_{W e t_{-} U}-P_{D r y_{-} U}=\varepsilon \sigma T_{U-W e t}^{4}-\varepsilon \sigma T_{U-D r y}^{4}
$$

where $P_{\text {WET } R}=P_{D R T_{-} R}$. Consider a maximum average upper estimate by assuming $\mathrm{T}_{\mathrm{U} \_ \text {Dry }}=30^{\circ} \mathrm{C}$. Then from Zhao et al.'s data, we should find on average $\mathrm{T}_{\mathrm{U}_{-} W e t}=33.3^{\circ} \mathrm{C}$ ( since we have assumed $\mathrm{T}_{\mathrm{R}_{-} \mathrm{Wet}^{-}}=\mathrm{T}_{\mathrm{R}_{-} \text {Dry }}$ ). This provides values that can be used for this difference radiation flux as an upper bound estimate of

$$
\Delta P_{W_{U}-D_{U}}=310.06 \mathrm{~W} / \mathrm{m}^{2}-296.92 \mathrm{~W} / \mathrm{m}^{2}=13.14 \mathrm{~W} / \mathrm{m}^{2}
$$

This yields a maximum difference water-vapor feedback of

$$
\left(\lambda_{W_{U}-D_{U}}\right)_{M a x}=13.14 \mathrm{~W} / \mathrm{m}^{2} / 3.3 \mathrm{~K}=3.98 \mathrm{~W} / \mathrm{m}^{2} /{ }^{\circ} \mathrm{K}
$$

By comparison, this maximum difference feedback of $4 \mathrm{~W} / \mathrm{m}^{2} /{ }^{\circ} \mathrm{K}$ is about $1 \mathrm{~W} / \mathrm{m}^{2} /{ }^{\circ} \mathrm{K}$ higher than the second difference feedback of $3.1 \mathrm{~W} / \mathrm{m}^{2} /{ }^{\circ} \mathrm{K}$ at the local UHI level. The water-vapor feedback is strongly positive, and Dessler et al. [6] estimated climate feedback of $\lambda=2.04 \mathrm{~W} / \mathrm{m}^{2} /{ }^{\circ} \mathrm{K}$. We note Dessler et al. studies that we are comparing our estimates to for various locations were similarly assessed (as in Eq. 5, 7, 8, and 10). Comparing

$$
\lambda_{q}=\left(\sum_{x, y, z} \frac{\partial R_{\text {OLR }}}{\partial q(x, y, z)} \frac{\Delta q(x, y, z)}{\Delta T_{S}}\right)_{\text {Dessleretal. }} \rightarrow\left(\sum_{\text {UHIs }} \frac{\Delta P_{\text {Wet-Dry, OLR-UHI }}}{\Delta T_{\text {Wet-Dry,S }}}\right)_{\text {UHIs, this article }}
$$

In the Dessler et al. equation, $\mathrm{R}$ is the outgoing global average radiative flux similar to $\Delta P, \Delta q$ is the water-vapor change from 2003-2007 at various coordinates (in our case this is the humid wet-dry cities mean sum resulting from city growth observed through rural to urban changes) and $\Delta T_{\mathrm{S}}$ is the surface temperature. The main difference is Dessler et al. used pre-computed values from other authors for $\partial \mathrm{R} / \partial \mathrm{q}(\mathrm{x}, \mathrm{y}, \mathrm{z})$, where values in Eq. 7 and 10 are from Zhao et al. direct warming observations. It is expected that one would find higher feedback values at lower altitudes since water-vapor and temperatures are higher especially in a humid environment. However, Dessler et al. did not focus on estimating the feedback attributed to humid areas at low portions of the troposphere due to UHI growth. Here we note that UHIs are a factor of 1.5 to 2 times higher in our analysis than Dessler's [6] averages. If all things were set equal for water-vapor feedback, one would expect higher values at lower altitudes in general. However, in this result, while lapse rate plays a role in the strength, feedback described here is very dependent on difference measurement of rural versus urban areas, it is a daytime precipitation effect, found by subtracting out humid from dry UHI environments, and is related strongly to impermeable surfaces.

\section{Conclusion}

It may be difficult to assess how UHI growth and with it local water-vapor feedback may affect global warming. Thermodynamic atmospheric effects are cumulative. Therefore, we consider atmospheric surface and dome-type WAVHIS a serious issue that likely impacts UHIs warming contributions. Therefore, one should not minimize its importance by stating that it is only of local significance. Certainly, it is a local concern for residence in UHI humid environments. The Dessler et al. conclusions attribute climate water-vapor feedback warming as a consequence of $\mathrm{CO}_{2}$ forcing and other GHGs. Dessler points out that as surface temperature increases so does water-vapor. This 
must also be true of UHIs. However, Dessler et al. [6] did not focus on quantifying UHI growth and local warming and water-vapor feedback issues which are found here to have strong effects.

In a study recently by the author [9], about $11 \%-16 \%$ of global warming was attributed to UHIs and land cover/land use. However, in that study, no additional amplification factor was provided to account for global warming contributions from the humidity effect over the numerous cities worldwide in humid environments [5, 11]. For example, an increase in this percentage of $25 \%$ may not be unreasonable. This is another important reason for albedo management of cities, roads, and rooftops to reduce undue risks and help mitigate the global warming crisis.

UHI growth incurs local water-vapor feedback that has a strong effect in humid environments, found here to be 1.5 to 2 times the global average $\left(3.1 \mathrm{~W} / \mathrm{m}^{2} \rho \mathrm{K}-4 \mathrm{~W} / \mathrm{m}^{2} \rho \mathrm{K}\right)$. It also likely plays a role in UHI warming contributions at the global level [9, 10]. We suggest that mitigation is important and best accomplished by albedo management. Albedo reverse forcing mitigation has many advantages [8, 10]. As well, there is a growing knowledge-base of UHI albedo controls and other reflectivity solutions. We recommend that UHI albedo mitigation is urgently needed [8, 9] as a supplement to $\mathrm{CO}_{2}$ efforts and should be advocated worldwide by policymakers.

Therefore, similar to our previous publications $[8,9,10]$, the following albedo management suggestions and corrective actions are recommended:

- Modification of the Paris Climate Accord to include albedo controls and solutions, especially in humid environments.

- Albedo guidelines for UHI impermeable surfaces, cool-roofs, roads, and other areas [10] as well similar to on-going $\mathrm{CO}_{2}$ efforts

- UHI albedo goals: we suggest an albedo increase by a factor of 4 (from typical UHI albedo value of 0.12), which could reduce global warming by about $30 \%$ or more, based on a study by the author [9]

- Government funding for geoengineering and implementation of albedo solutions

- Centralize albedo solution efforts in a single government agency (possibly NASA)

- Guidelines for future albedo design considerations of urbanization areas such as requiring all new buildings to have flat roofs with highly reflective surfaces

- Requires cars to be more reflective. Although worldwide vehicles do not comprise much of the Earth's solar area, recommending the preferential manufacturing of cars that are higher in reflectivity (e.g., silver or white) would raise awareness of this issue similar to electric automobiles that help improve $\mathrm{CO}_{2}$ emissions increasing interest in urbanized albedo management. There are an estimated 1.4 billion vehicles in operation. As well, a cooler car will reduce $\mathrm{AC}$ needs improving fuel consumption and less $\mathrm{CO}_{2}$ emissions by about $2 \%[40]$.

\section{Conflicts of Interest}

The author declares that he has no conflicts of interest. 


\section{References}

1. Zhao L., Lee X, Smith R., Oleson K. (2014) Strong, contributions of local background climate to urban heat islands, Nature. 10;511(7508):216-9. DOI: 10.1038/nature13462

2. Gunawardena K, Wells M, Kershawa T (2017) Utilizing green and blue space to mitigate urban heat island intensity,ScienceDirect, doi: 10.1016, https://www.sciencedirect.com/science/article/pii/S0048969717301754

3. Fan, Y., Li, Y., Bejan, A. et al. Horizontal extent of the urban heat dome flow. Sci Rep 7, 11681 (2017). https://doi.org/10.1038/s41598-017-09917-4

4. Cao C., Zhao J, Gong P, MA G., Bao D., Tian K., Wetland changes and droughts in southwestern China, Geomatics, Natural Hazards and Risk, Oct 2011,

5. https://www.nasa.gov/mov/291251main_L3_H2O_Final_576.mov, The distribution of atmospheric water vapor, variation in time across the globe. During the summer and fall of 2005, this visualization shows that most vapor collects at tropical latitudes, particularly over south Asia, where monsoon thunderstorms swept the gas some 2 miles above the land.

6. Dessler A., Zhang Z., Yang P., (2008) Water-vapor climate feedback inferred from climate fluctuations, 2003-2008, Geophysical Research Letters, https://doi.org/10.1029/2008GL035333

7. Hansen K. (2008) NASA's Goddard Space Flight CenterWater Vapor Confirmed as Major Player in Climate Change, NASA, https://www.nasa.gov/topics/earth/features/vapor_warming.html, last accessed $12 / 21 / 2020$

8. A. Feinberg, A Re-radiation Model for the Earth's Energy Budget and the Albedo Advantage in Global Warming Mitigation, in Peer Review, pre-print available at ResearchGate. DOI:10.13140/RG.2.2.11785.26727, vixra 2010.0143

9. Feinberg A, (2020) Urban heat island amplification estimates on global warming using an albedo model. SN Appl. Sci. 2, 2178 (Dec. 2020). https://doi.org/10.1007/s42452-020-03889-3.

10. Feinberg A, (2020) On Geoengineering and Implementing an Albedo Solution with Urban Heat Islands Global Warming and Cooling Estimates, in Peer Review, pre-print available at ResearchGate DOI: 10.13140/RG.2.2.26006.37444, vixra 2006.0198

11. Wikipedia, https://en.wikipedia.org/wiki/Humidity, last access 1/10/2021. 
Figures

\section{Daytime Humid}

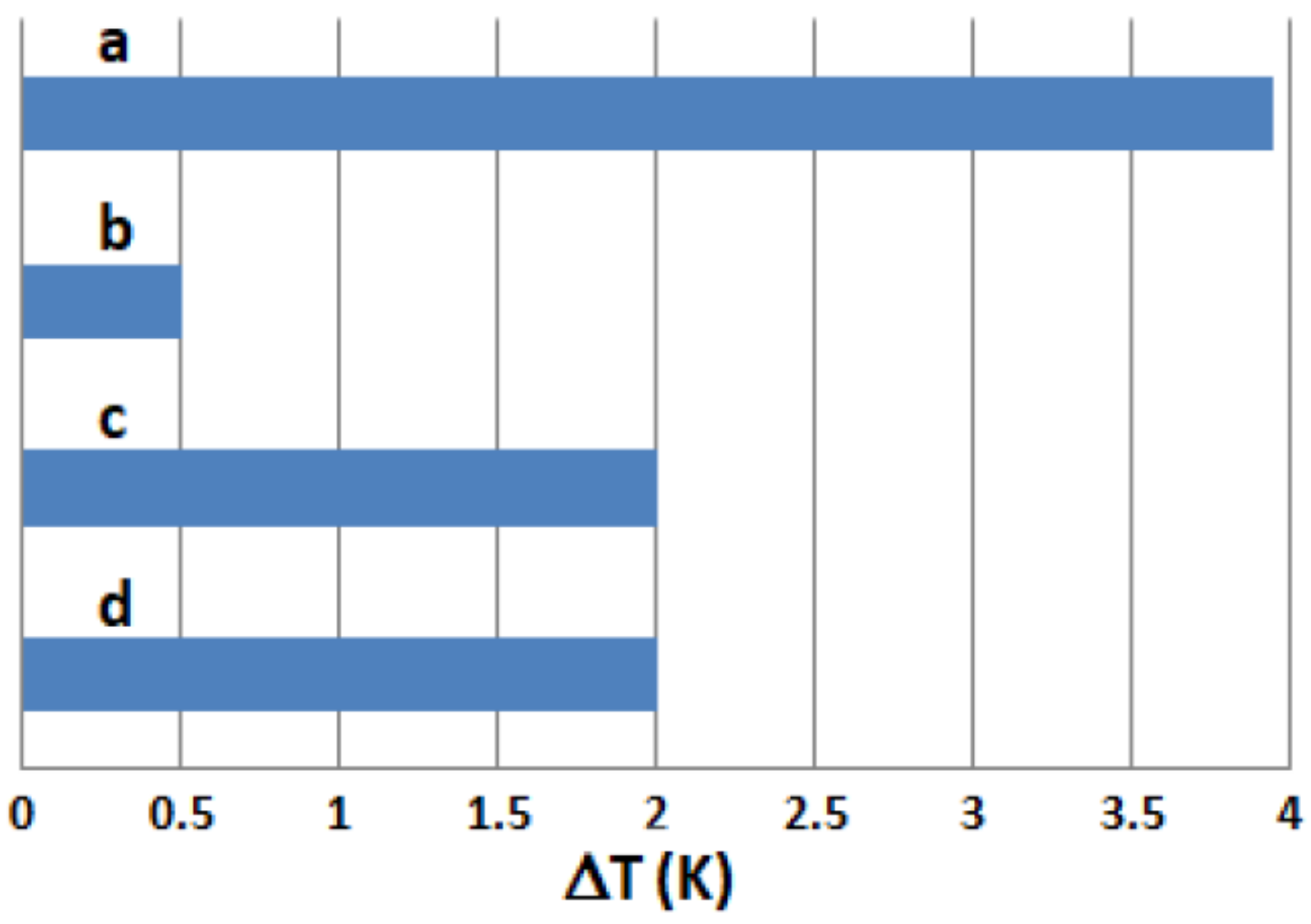

Figure 1

Key estimates taken from Zhao et al. [1] MODIS 4 T data (see their Fig. 2 [1]) values assessed are a) daytime value of humid cities, b) daytime in wet cities, c) and d) are night humid and dry cities 